\title{
Acroosteólisis en esclerosis sistémica
}

\section{Acroosteolysis in systemic sclerosis}

\author{
Andrea Facio-Lince, Miguel Antonio Mesa • Medellín (Colombia)
}

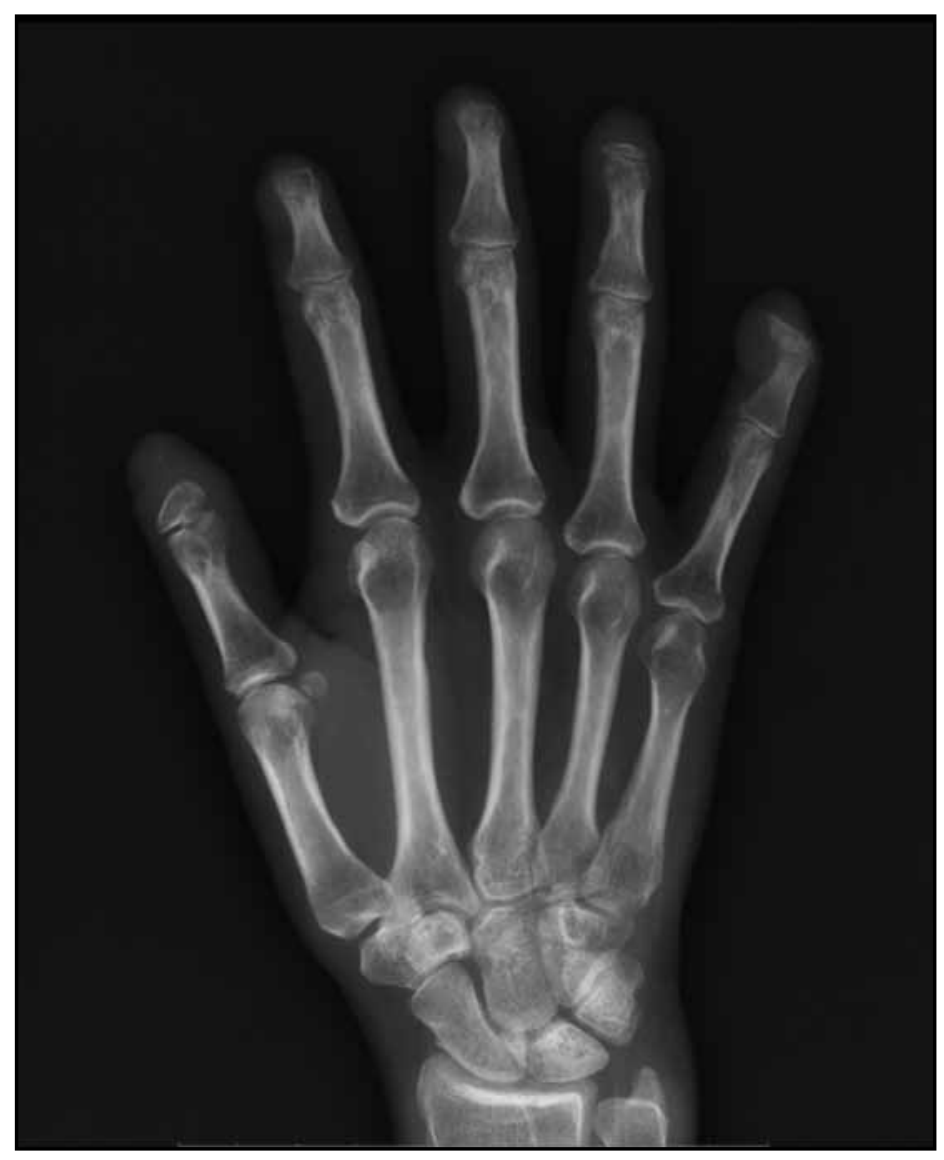

Figura 1a. Rayos $X$ de mano derecha donde se observa la reabsorción de las falanges distales y los tejidos blandos.

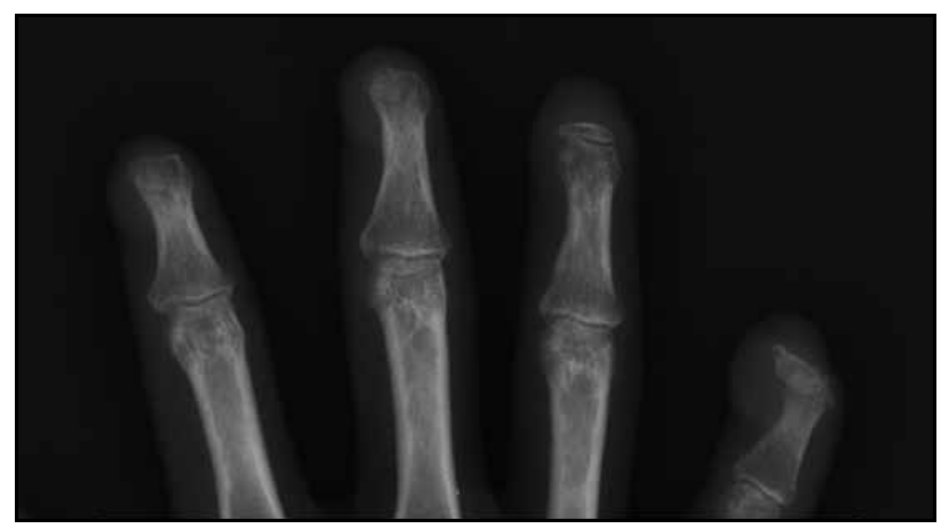

Figura 1b. Magnificación de las falanges distales para mayor detalle.
Paciente femenina de 42 años de edad, con diagnóstico de esclerosis sistémica de larga data. Clínicamente la paciente presentaba esclerosis cutis, fenómeno de Raynaud, calcinosis, enfermedad pulmonar intersticial y compromiso gastrointestinal dado por reflujo gastroesofágico.

Consultó por dolor y deformidad en las falanges distales asociado a reabsorción del lecho ungular. A los rayos x se observó la desaparición tanto de la falange distal como de los tejidos blandos circundantes (Figuras 1a y 1b).

La acroosteolisis y reabsorción de la falange distal son hallazgos raros en las enfermedades reumatológicas. Característicamente se presentan en la psoriasis con afección de interfalángicas distales (1) y en la esclerosis sistémica, afectando en esta última entre 15 y $22 \%$ de los pacientes. Se asocia con diversas manifestaciones como: compromiso pulmonar, esofágico (2), úlceras digitales, terapia con prostaciclinas, calcinosis e hipertensión pulmonar (3). Siendo un hallazgo altamente específico tiene alta utilidad diagnóstica en reumatología.

\section{Referencias}

1. Ory PA, Gladman DD, Mease PJ. Psoriatic arthritis and imaging. Ann Rheum Dis. 2005 Mar; 64 Suppl 2: ii55-7.

2. Erre GL, Marongiu A, Fenu P, Faedda R, Masala A, Sanna M, et al. The "sclerodermic hand": a radiological and clinical study. Joint Bone Spine. $2008 \mathrm{Jul}$; 75(4): 426-31.

3. Avouac J, Guerini H, Wipff J, Assous N, Chevrot A, Kahan A, et al. Radiological hand involvement in systemic sclerosis. Ann Rheum Dis. 2006; 65(8): 1088-92.
Andrea Facio-Lince García: Estudiante de VIII semestre de medicina, Escuela de Ciencias de la Salud, Universidad Pontificia Bolivariana; Dr. Miguel Antonio Mesa: Docente Asistente Escuela de Ciencias de la Salud, Universidad Pontificia Bolivariana. Médico Reumatólogo Clínica Universitaria Bolivariana. Medellín, Colombia.

Correspondencia: Dr. Miguel Antonio Mesa. Medelllín (Colombia). E-mail: miguel.mesa@upb.edu.co

Recibido: 20/VII/2015 Aceptado: 5/VIII/2016 